\title{
A RELAÇÃO DA POSTURA CORPORAL, DA RESPIRAÇÃO ORAL E DO ESTADO NUTRICIONAL EM CRIANÇAS - UMA REVISÃO DE LITERATURA
}

\author{
Relation of body posture, oral breath and nutritional status \\ in children - a literature review
}

Patrícia Girarde Machado ${ }^{(1)}$, Carolina Lisbôa Mezzomo ${ }^{(2)}$

\begin{abstract}
RESUMO
Tema: a relação entre o estado nutricional, a respiração oral e a postura corporal. Uma alimentação balanceada capaz de proporcionar um adequado estado nutricional, certamente, contribui para uma desejável condição postural e a respiração nasal do indivíduo. Sob o aspecto respiratório, em crianças respiradoras orais por haver maior alteração no sono, diminuição da ingestão de carboidratos e aumento da ingestão de lipídeos, pode haver a associação entre a respiração oral e o estado nutricional também. Objetivo: apresentar as possíveis relações entre estado nutricional, respiração oral e a postura corporal em crianças, por meio de um estudo teórico. Conclusão: segundo os artigos pesquisados é a obesidade, dentre os distúrbios nutricionais, o que gera maior número de problemas musculoesqueléticos, pois dificulta o controle da postura corporal. Conclui-se que apesar de haver fortes argumentos teóricos buscando explicar uma possível influência da respiração oral sobre o estado nutricional, os estudos de campo até o momento não conseguiram confirmar tal hipótese, por esta razão torna-se relevante continuar pesquisando sobre estas relações.
\end{abstract}

DESCRITORES: Postura; Respiração; Respiração Bucal; Estado Nutricional; Criança

\section{INTRODUÇÃO}

As pesquisas até agora realizadas estão de acordo com o fato de que o acompanhamento da situação nutricional das crianças constitui um instrumento fundamental para aferição das condições de saúde da população infantil e monitoramento da evolução da qualidade de vida da população em geral ${ }^{1,2}$.

O estado nutricional exerce influência decisiva nos riscos de morbimortalidade e no crescimento e desenvolvimento infantil, o que torna importante uma avaliação nutricional da população mediante procedimentos diagnósticos que possibilitem

(1) Fisioterapeuta; Professora Substituta da Universidade Federal de Santa Maria, UFSM, Santa Maria, RS; Brasil; Especialista em Atividade Física, Desempenho Motor e Saúde.

(2) Fonoaudióloga; Professora Adjunta da Universidade Federal de Santa Maria, UFSM, Santa Maria, RS, Brasil; Doutora em Linguística Aplicada.

Conflito de interesses: inexistente precisar a magnitude, o comportamento e os determinantes dos agravos nutricionais, assim como identificar os grupos de risco e as intervenções adequadas. Variáveis como renda familiar, escolaridade, entre outras, estão condicionadas à forma de inserção das famílias no processo de produção, refletindo na aquisição de alimentos e, conseqüentemente, no estado nutricional ${ }^{1-3}$.

Dessa forma, alguns estados carenciais, ou mesmo a ingestão de alguns componentes alimentares específicos, podem influenciar o desenvolvimento e crescimento do corpo de cada individuo.

Dada a complexidade biomecânica da postura, que possibilita a integração funcional dos vários segmentos, é possível entender que, frente à alteração de uma unidade biomecânica, ocorra refinamento dos sistemas de controle postural, acomodações das estruturas corporais próximas ou distantes por meio de compensações ${ }^{4}$.

Sendo assim, a adequação postural assume importância na abordagem dos indivíduos em desenvolvimento, uma vez que ao se alterarem as 
relações espaciais fisiológicas surgirão desbalanceamentos musculares, estiramentos capsuloligamentares e desalinhamento dos segmentos corporais com conseqüentes alterações adaptativas dos ossos no sentido de se acomodarem às novas condições mecânicas impostas. Este conjunto de eventos induz ao aparecimento de deformidades definitivas na vida adulta ${ }^{5}$.

Dentre as populações de risco, as crianças em idade pré-escolar constituem um grupo altamente vulnerável à deficiência de ferro, o que suscita grande preocupação na área de saúde pública em razão dos prejuízos que acarreta ao desenvolvimento dessas crianças ${ }^{3}$.

A adoção de hábitos alimentares saudáveis na infância contribui para o pleno crescimento e desenvolvimento da criança e para a prevenção de doenças, refletindo na qualidade de vida familiar ${ }^{6}$.

A relação entre o estado nutricional, a respiração oral e a postura corporal ainda não está bem esclarecida. Há certa concordância em que a postura, o estado nutricional e a respiração oral estão interrelacionados, porém há poucos dados disponibilizados na literatura para confirmar esta afirmação e para estabelecer qual seria a natureza de qualquer relação possível. Uma alimentação balanceada capaz de proporcionar um adequado estado nutricional, certamente, contribui para uma desejável condição postural e a respiração nasal do indivíduo.

Observa-se que a relação da respiração oral com a modificação no processo geral de alimentação, associada às dificuldades no olfato, paladar e distúrbios miofuncionais orofaciais podem repercutir no estado nutricional e isto, de certa forma, prejudica o desenvolvimento e equilíbrio postural, levando a alterações posturais comuns como hiperlordose, cifose e até mesmo, alterações posturais mais graves como escoliose. Portanto, ressalta-se a importância de uma abordagem interdisciplinar na atenção deste problema.

De acordo com o exposto, este trabalho tem como objetivo apresentar possíveis relações entre estado nutricional, respiração oral e a postura corporal de crianças por meio de uma revisão de literatura.

\section{MÉTODOS}

O presente estudo foi realizado a partir de uma revisão da literatura especializada e com a qual se buscou construir um referencial teórico sobre a relação da postura corporal, da respiração oral e do estado nutricional em crianças.

Foi realizado um levantamento bibliográfico durante o ano de 2009 e 2010, priorizando os estudos nacionais. A fim de se atingir o objetivo do estudo foi realizada uma pesquisa na busca de artigos publicados em diferentes bases de dados, a saber: MEDLINE, SCIELO e LILACS. Utilizou-se como critério de seleção o assunto do artigo, como também ao ano de publicação do mesmo, devendo ter sido publicado nos últimos 10 anos. Também foram utilizados alguns livros, sendo esses utilizados devido a sua grande importância para a área científica.

Para a realização da pesquisa utilizou-se as seguintes palavras chaves: postura corporal, respiração oral e estado nutricional pesquisadas no Decs - Descritores em Ciências da Saúde. Os temas foram relacionados e organizados em ordem de assuntos.

\section{REVISÃO DA LITERATURA}

A postura corporal junto com a respiração representa o equilíbrio corporal entre as forças internas e externas, tendo em vista serem estado e função que parecem se relacionar. A nutrição, por outro lado, representa nossa vida, já que o organismo humano consome energia proveniente da alimentação, tanto para suas tarefas fisiológicas diárias quanto para desencadear o processo de crescimento, constituindo assim requisitos importantes para uma vida saudável.

\section{Estado Nutricional}

Os seres humanos desenvolveram mecanismos fisiológicos contra a perda de massa corporal em períodos de escassez de alimentos, mas ainda não existe nenhum mecanismo capaz de prevenir o ganho de massa corporal na presença de alimentos abundantes e/ou inapropriados, situação relativamente recente na história da humanidade ${ }^{7}$.

Ao mesmo tempo em que declina a ocorrência da desnutrição em crianças e adultos num ritmo bem acelerado, aumenta a prevalência de sobrepeso e obesidade na população brasileira. Um antagonismo de tendências temporais entre desnutrição e obesidade foi estabelecido, definindo, dessa forma, uma das características marcantes do processo de transição nutricional nacional ${ }^{8}$.

A avaliação do estado nutricional é uma etapa fundamental no estudo de uma criança, para que possamos verificar se o crescimento está se afastando do padrão esperado por doença e/ou por condições sociais desfavoráveis. Ela tem por objetivo verificar o crescimento e as proporções corporais em um indivíduo ou em uma comunidade, visando estabelecer atitudes de intervenção. Assim, quanto mais populações e/ou indivíduos são avaliados do ponto de vista nutricional, e quanto mais seriadas são essas avaliações, mais intervenções precoces 
podem ser instituídas, certamente melhorando a qualidade de vida da população de uma forma geral. Assim, não existe forma de diminuir a desnutrição se ela não for diagnosticada de maneira adequada ${ }^{1}$.

No estudo de Castro et al. (2005) ${ }^{3}$, analisouse o consumo alimentar, o ambiente socioeconômico e o estado nutricional de pré-escolares em creches municipais de Viçosa, MG. Os nutrientes analisados foram proteínas, ferro, cálcio, vitamina A e vitamina C. Observou-se que, com exceção da proteína, todos os demais nutrientes, vitaminas e minerais encontravam-se abaixo da necessidade média estimada (EAR) para a faixa etária em estudo. Verificou-se que $75,7 \%$ das crianças apresentaram inadequação da ingestão energética em relação à necessidade energética estimada (EER). As freqüências de consumo dos grupos alimentares pelas crianças, sendo cada grupo representado pelo alimento mais consumido na freqüência de quatro a sete vezes por semana, foram margarina (doces e gorduras), banana (frutas), batata (raízes e tubérculos), frango (carnes), alface (hortaliças), feijão (leguminosas), leite (leite e derivados) e arroz (cereais e massas). Os resultados permitem verificar que as maiores freqüências de consumo estavam nos grupos dos cereais e massas, leguminosas, leite e derivados e doces e gorduras. Observou-se baixa freqüência no consumo de frutas, hortaliças e raízes e tubérculos. Também o consumo de carnes foi pouco freqüente, visto que se constatou $25,7 \%$ dos pré-escolares consumindo carne raramente, $53,8 \%$ de uma a três vezes por semana, e apenas $20,5 \%$ de quatro a sete vezes por semana.

A avaliação nutricional determina o estado nutricional, que é resultante do balanço entre a ingesta e a perda de nutrientes. $O$ estado nutricional de uma população é um excelente indicador de sua qualidade de vida ${ }^{1}$.

A desnutrição infantil tem determinantes multicausais, com condicionantes biológicos e sociais que se relacionam com o atendimento (ou não) de suas necessidades básicas, como saúde, saneamento, educação e alimentação. Quanto à alimentação, os inquéritos dietéticos tornam-se instrumentos importantes para avaliação do consumo alimentar, pois permitem a identificação de deficiências de macro e micronutrientes, assim como o conhecimento dos hábitos alimentares. As carências nutricionais, em especial a desnutrição energético-protéica, a anemia e a deficiência de vitamina A representam um dos principais problemas de saúde infantil, as carências de vitamina $A$, zinco e ferro normalmente não ocorrem isoladamente ${ }^{3}$.

A nutrição implica na ingestão e absorção dos nutrientes, bem como nos seus efeitos sobre os processos metabólicos e está relacionada ao equilíbrio entre o aporte e o consumo fisiológico de energia e nutrientes, ambas participando do processo de determinação do estado nutricional dos indivíduos ${ }^{6}$.

A avaliação miofuncional orofacial é importante nos estudos que investigam os aspectos nutricionais, especialmente nas crianças. A observação direta das funções estomatognáticas, como a mastigação, pode revelar dificuldades na alimentação que repercutem diretamente sobre o estado nutricional. Ao abrir a boca para respirar, há adaptações e desequilíbrio das estruturas e funções orofaciais que comprometem a mastigação e a deglutição, e, conseqüentemente, gera dificuldades na alimentação ${ }^{9}$.

É importante ressaltar que as alterações das funções estomatognáticas podem iniciar desde a época da transição do aleitamento natural para o artificial. A maioria das crianças do estudo de Cunha et al. $(2007)^{10}$, independentemente do grupo, foi amamentada por um período inferior a quatro meses. O desmame precoce pode levar à ruptura do desenvolvimento motor-oral adequado, provocando alterações na postura e força dos órgãos fonoarticulatórios e prejudicando as funções de mastigação, deglutição, respiração e articulação dos sons da fala. A falta da sucção fisiológica ao peito pode interferir no desenvolvimento motor-oral, possibilitando a instalação de má oclusão, alteração motora-oral e da respiração oral.

\section{O estado nutricional e a respiração oral}

A respiração é uma função vital para o ser humano, e sua qualidade está diretamente ligada à qualidade de vida do homem. A respiração também é fundamental para o desenvolvimento e manutenção da saúde das estruturas orofaciais ${ }^{11}$.

A respiração oral é um dos sintomas mais freqüentes na infância e o número de pacientes respiradores orais vem aumentando gradativamente em função da poluição, e conseqüentemente, do aumento dos agentes alérgicos, cada vez mais presentes no ar e nos alimentos ${ }^{12}$.

Os distúrbios respiratórios, muito freqüentes em crianças, podem variar desde pequenos processos alérgicos até quadros mais graves como a apnéia do sono. A rinopatia alérgica acomete criança de qualquer idade, entretanto, por se apresentar com sintomas mais leves, muitas vezes seu diagnóstico é feito mais tardiamente. Já a hiperplasia adenoamigdaliana têm sua maior incidência entre 3 e 6 anos de idade. Por seus sintomas serem muitos comuns, os distúrbios respiratórios do sono na criança podem ter seu diagnóstico retardado, podendo chegar há 2 anos ${ }^{13}$. 
A criança que não respira eficientemente pelo nariz mantém a boca aberta, e em decorrência desta respiração de suplência oral pode apresentar sintomas variados, que alteram sua dinâmica alimentar e levam à alteração do estado nutricional ${ }^{14}$.

Outras características de crianças respiradoras orais são o cansaço freqüente, sonolência diurna, adinamia, apetite reduzido, enurese noturna, déficit de aprendizado e, até, alterações nutricionais ${ }^{13}$.

A relação da respiração oral com a modificação no processo geral de alimentação, associada muitas vezes ao acometimento de estruturas como a arcada dentária, às mudanças no processo mastigatório, dificuldades no olfato, paladar, distúrbios miofuncionais orofaciais, podem repercutir diretamente no estado nutricional. O respirador oral, geralmente, apresenta olfato e paladar diminuídos. Assim, a opção pelo tipo de alimento não é feita pelo apetite, mas pela consistência e facilidade de ingestão, permitindo que o paciente continue respirando pela boca ${ }^{9,14}$.

A respiração oral pode ocorrer por obstrução mecânica e/ou por hábito na ausência de impedimento orgânico, o que leva a inúmeras e variadas alterações na cavidade oral, na face e no organismo em geral, tornando importante, muitas vezes, a avaliação do paciente por uma equipe multidisciplinar. Por definição, o respirador oral é aquele indivíduo que respira predominantemente pela boca por um período de pelo menos seis meses, a partir de qualquer idade, independentemente da causa ${ }^{15}$.

As associações entre alteração no estado nutricional e a respiração oral ainda não estão totalmente esclarecidas na literatura, principalmente em relação ao sobrepeso/obesidade. Porém, algumas associações reforçam a hipótese do envolvimento da modificação do modo respiratório e a presença de condições nutricionais inadequadas, podendo levar o indivíduo, na maioria das vezes, à um déficit pôndero-estatural. Nos respiradores orais, a má oclusão (casos de mordida aberta ou cruzada, ausência de elementos dentários anteriores, entre outros) também é responsável pelo funcionamento inadequado das funções orofaciais e pode causar interferências na mastigação, levando ao predomínio unilateral e modificando o tempo para mastigar. Embora os estudos mostrem possível relação entre respiração oral e mudanças no processo alimentar, com conseqüente interferência no estado nutricional, observam-se poucos estudos nacionais acerca dessas alterações, tornando-se relevante a sua investigação ${ }^{9}$.

Na pesquisa de Rodrigues et al $(2005)^{16}$, quanto à deglutição, pôde ser observada uma grande prevalência de sujeitos com alteração $(77,42 \%)$, todavia, o resultado estatístico não foi confiável. Portanto, não foi confirmada a associação entre deglutição e modo respiratório, apesar da literatura indicar que o padrão respiratório pode influenciar o desenvolvimento orofacial, incluindo as funções estomatognáticas. Comparando jovens com respiração oral e nasal, todos com deglutição atípica, os respiradores orais exibiram uma freqüência mais alta de distooclusão, mordida aberta, mordida cruzada e apinhamento.

$\mathrm{Na}$ avaliação das funções estomatognáticas, na pesquisa de Rodrigues et al (2005) ${ }^{16}$ observou-se 22 sujeitos $(70,97 \%)$ apresentando mastigação alterada, sendo em $15(68,20 \%)$ predominantemente unilateral direita e em 7 (31,80\%) predominantemente unilateral esquerda. Quanto à deglutição 24 sujeitos $(77,42 \%)$ apresentaram alterações, sendo que $20(83,34 \%)$ realizaram projeção anterior de língua, dois $(8,33 \%)$ projeção lateral e outros dois $(8,33 \%)$ contração da musculatura perioral. $\mathrm{Na}$ correlação das variáveis modo respiratório e alterações encontradas no sistema estomatognático concluiu-se que existiu associação estatisticamente significante entre respiração oral/oronasal e presença de lábios entreabertos ou abertos $(p<0,001)$, presença de língua alargada $(p=0,020)$, flacidez de lábios $(p<0,001)$ e flacidez da língua $(p=0,003)$.

No trabalho de Andrade e Silva et al.(2007) ${ }^{17}$, as diferenças encontradas entre os grupos de Respiradores Nasais (RN) e Respiradores Orais (RO) foram: tempo de mastigação, pois o grupo RO apresentou mastigação mais rápida que o $\mathrm{RN}$; ausência de restos de alimento no grupo $\mathrm{RN}$ e presença de restos no vestíbulo da boca no grupo $\mathrm{RO}$; ausência de ruído no grupo $\mathrm{RN}$ e presença de ruído durante a mastigação no grupo $\mathrm{RO}$; e lábios fechados no grupo RN e abertos no grupo RO. Estes puderam concluir que a respiração oral interfere em determinados aspectos da função mastigatória. Desta forma, é de extrema importância que durante a avaliação da mastigação seja levado em conta o modo respiratório de cada indivíduo. A respiração oral modifica, em muitos casos, o funcionamento e as estruturas que compõem o sistema estomatognático e o indivíduo não pode mastigar corretamente o alimento, devido à necessidade de respirar. Como a necessidade respiratória é superior à de mastigar, o tempo de mastigação tem que ser considerado. Essas duas funções utilizam a mesma via, o mesmo trajeto. Além da duração diminuída da mastigação, observa-se também a diminuição dos golpes mastigatórios, pois o indivíduo que respira pela boca evita alimentos com maior consistência.

Poucas são as explicações para justificar a mudança do peso corporal do indivíduo respirador 
oral. Algumas delas relacionam-se às mudanças no processo mastigatório e à dificuldade de deglutição, causadas pela obstrução faríngea, nasal ou palatina; outra se refere à diminuição do olfato pela obstrução nasal crônica, alterando o paladar ${ }^{18}$.

No trabalho de Cunha et al $(2007)^{10}$ a possibilidade de que crianças com respiração oral podem desenvolver alterações no estado nutricional não foi confirmada, observando-se predominância de indivíduos eutróficos e ausência de diferença significante nas freqüências de crianças com peso baixo e sobrepeso entre os grupos de Respiradores Orais e Nasais. Também não foi observada diferença estatística quanto ao paladar e ao olfato entre os grupos. No entanto, é relatada a relação entre esses dois aspectos nos indivíduos com respiração oral, em virtude da não utilização adequada das vias aéreas superiores, sendo comum a queixa de hipogeusia. Porém, há referência sobre a diminuição da ingestão de carboidratos e aumento da ingestão de lipídeos em crianças respiradoras orais com baixo peso e eutróficas quando comparadas às crianças respiradoras nasais com o mesmo estado nutricional.

Já no estudo de Carnevalli, Nozaki e Araújo $(2009)^{19}$ o qual teve por objetivo avaliar o estado nutricional de crianças respiradoras orais a fim de se verificar sua relação com a obesidade, participaram 35 crianças entre 5 e 10 anos, avaliadas através de um questionário composto por uma avaliação antropométrica (classificação Waterlow, Percentis, Escore Z: P/I, E/I e P/E, CB e RCQ) e questionamentos sobre o padrão respiratório oral, preferências alimentares, entre outros. Os resultados observados demonstraram haver um índice acima dos $50 \%$ de crianças com sobrepeso, obesidade ou obesidade mórbida, além da alteração do padrão alimentar, que faz com que a criança coma rápido, ingerindo alimentos acima do necessário. As crianças demonstraram uma ingestão de quase $100 \%$ de carboidratos e mais de $60 \%$ de lipídios acima do padrão recomendado. Os achados, neste estudo, confirmam o que é descrito em literatura, demonstrando que a respiração oral provoca distúrbios na mastigação e alimentação que podem levar à obesidade.

O respirador oral pode apresentar inúmeras características, dentre elas: crescimento craniofacial com predominância vertical; hipertrofia adenoamigdaliana, diminuição do tônus e hipofunção dos músculos levantadores da mandíbula; alteração de tônus com hipofunção dos lábios e bochechas; lábio superior retraído ou curto e inferior com eversão ou interposto entre os dentes; olheiras (cianose infraorbitária) com assimetria de posicionamento dos olhos; hipercontração do músculo mentual. A diminuição do tônus nos músculos da face, em especial dos bucinadores e zigomáticos maior e menor, configura o que se denomina de flacidez facial, acarretando à face baixa resistência à tração, com aspecto de "face caída", e produzindo efeitos de envelhecimento precoce. O bucinador é um músculo mímico responsável pela flacidez facial presente nos respiradores orais e diretamente relacionado aos sinais de envelhecimento. Este músculo confere a imagem facial do indivíduo, pois se encontra no centro de cada hemiface, proporcionando equilíbrio e simetria. Outros achados: alteração de oclusão, classe II de Angle (mandíbula pode se encontrar em posição mais distal em relação à maxila); palato ogival; hipodesenvolvimento da maxila e mandíbula, alteração na erupção dentária ${ }^{20-22}$.

\section{O estado nutricional e a postura corporal}

Toda alteração funcional provoca uma alteração em cadeia nos segmentos subjacentes, ou seja, em todo o complexo articular e muscular do corpo. Cada vez que um músculo se encurta, ele aproxima suas extremidades e, conseqüentemente, afeta os ossos nos quais está inserido, desorganizando outros músculos que tenham origem ou inserção nos mesmos ossos, e assim sucessivamente. Uma alteração em qualquer nível da coluna vertebral promove compensações nas curvaturas vizinhas ${ }^{23}$.

Quando se desenvolve uma postura anormal é necessária a atuação de maior número de fibras musculares, mesmo de músculos que originalmente não estão envolvidos com a manutenção da postura normal. A seqüência de acionamento das fibras musculares se torna irregular e mais intensa, e a fadiga surge mais precocemente ${ }^{5}$.

A obesidade, dentre os distúrbios nutricionais, é o que gera maior número de problemas musculoesqueléticos. Os períodos críticos de surgimento da obesidade progressiva são os 12 primeiros meses de vida, a fase pré-escolar e a puberdade. A obesidade progressiva se associa à obesidade hiperplásica, dificultando o controle de peso corporal, na idade adulta inferindo a importância de estudos frente a essa população no referido contexto do ganho de peso excessivo e de sua contribuição para uma alteração na postura ${ }^{8}$.

Na pesquisa de Mello (2002) ${ }^{1}$ é ressaltado que o estudo do crescimento físico de crianças indígenas xavantes já não demonstrou tão bom estado nutricional, fato mais habitualmente encontrado quando se avalia populações indígenas. A desnutrição de populações indígenas as coloca em situações de risco, nas quais as mudanças socioeconômicoculturais impostas a estas populações são certamente os fatores determinantes. A população 
indígena do Alto Xingu estudada segue os princípios de uma boa nutrição. As crianças são amamentadas de forma exclusiva durante o primeiro ano de vida, e de forma mista até os 3 anos de idade. Ingerem uma variedade de alimentos, mantendo um representante de cada classe: mandioca, peixe, ovos e frutas silvestres. Ingesta bem diferente da tendência mundial, onde o consumo de alimentos de origem animal, de açúcares e de farinhas refinadas é alto, e o de cereais integrais e fibras é baixo. Esse estudo salienta uma população com boa qualidade de vida, já que tem oferta de alimentos saudáveis e não é possuidora de doenças crônicas e más condições ambientais que determinem desequilíbrio entre a ingesta e o gasto calórico. Outro dado de extrema importância é a pequena incidência de obesidade, fato contrário à tendência da população industrializada mundial, demonstrando que uma dieta variada, na ausência de sedentarismo e de modismos da vida industrializada, como fast food e produtos alimentares industrializados, diminui 0 risco de obesidade.

No trabalho de Bankoff et al $(2003)^{24}$, foram estudadas as alterações morfológicas do sistema locomotor associadas à obesidade em 19 sujeitos de ambos os sexos, os quais foram divididos em três grupos, sendo: $\mathrm{G} 103$ sujeitos masculinos com média de idade 17,0 anos; G2 04 sujeitos femininos com média de idade 15,5 anos e G3 12 sujeitos do sexo feminino com média de idade 46,8 anos, pertencentes ao "Programa de atividade física para crianças, adolescentes e adultos obesos", oferecido em parceria com o Ambulatório de Pediatria do Hospital das Clínicas e o Laboratório de Eletromiografia e Biomecânica da Postura - Faculdade de Educação Física. A postura hiperestendida dos joelhos, com inclinação pélvica e inclinação do corpo à frente, e mais os desvios da coluna vertebral, deixam estes obesos com muita dificuldade de locomoção, desordem no equilíbrio postural e diminuição da estabilidade corporal postural. A lordose cervical esteve presente em todos os sujeitos estudados, independentemente do sexo e da idade, apresentando como conseqüência, além de um desvio postural, uma alteração morfológica muito importante para a postura corporal, que é a diminuição da distância do meato acústico externo e ombro, causando também várias dobras na região do pescoço.

No sujeito obeso, a manutenção do equilíbrio postural e a estabilidade corporal são mais difíceis, principalmente durante a marcha e a locomoção, muito embora a base de apoio, que representa a posição dos pés, a qual inclui a área sob e entre os pés, seja proporcional à morfologia estrutural de cada sujeito. Outros fatores também se refletem na estabilidade da manutenção do equilíbrio postural, como, por exemplo: distribuição da massa corporal, altura do centro de gravidade, relações antropométricas diferenciadas entre as estruturas anatômicas (tronco/tórax/abdome/pelve), membros inferiores e posição dos pés ${ }^{24}$.

A pesquisa de Bachiega $(2006)^{5}$ consistiu de 389 escolares, faixa etária entre 6 e 15,9 anos, de ambos os gêneros, de uma escola privada e duas públicas, provenientes da área urbana de Penápolis que estavam matriculados e cursando o ensino fundamental no ano letivo de 2004. Avaliou-se uma sala da $1^{\underline{a}}$ a $8^{\underline{a}}$ série do ensino fundamental, no caso de mais de uma classe por série foi escolhida por meio de sorteio. Obteve-se como resultado alta prevalência de sobrepeso $(14,91 \%)$ e obesidade $(15,68 \%)$ nos escolares avaliados. O gênero feminino obteve $18,56 \%$ e $11,32 \%$ e o masculino $10,11 \%$ e $21,42 \%$, respectivamente, para sobrepeso e obesidade. Considerando-se os sobrepesos e obesos verificou-se uma prevalência de 30,59\% dos escolares avaliados. Em relação ao estado nutricional e gênero, as alunas totalizaram $29,88 \%$ de sobrepeso e obesidade, nos escolares do gênero masculino observou-se $31,53 \%$.

$\mathrm{Na}$ relação do estado nutricional com a postura corporal, os escolares obesos apresentaram maior proporção de pés planos que os demais estados nutricionais. Os resultados do presente estudo ressaltam que a obesidade em crianças e adolescentes na idade escolar é um problema crescente e preocupante, principalmente pelos maiores riscos de morbi-mortalidade na idade adulta. Em relação ao estado nutricional e valores angulares da curvatura lombar, evidencia-se que a curvatura lombar apresenta nítida tendência a maiores valores angulares nos percentis referentes a sobrepeso e obesidade em ambos os gêneros, sendo mais importante para o gênero masculino ${ }^{5}$.

Na pesquisa de Junior et al. $(2008)^{25}$, com relação a avaliação dos hábitos posturais, não houve diferença estatística significativa entre as crianças obesas e eutróficas. Entretanto, na avaliação postural, $46(82,14 \%)$ das crianças obesas apresentaram hiperlordose lombar, ao passo que, 112 $(51,85 \%)$ das crianças eutróficas apresentaram esta variação postural. Ainda, na avaliação postural, foram avaliados 103 (59,54\%) joelhos valgos em crianças obesas, ao passo que, no grupo de eutróficos foram detectados $296(31,12 \%)$ joelhos valgos, nas outras variações posturais não foram encontrados resultados estatisticamente significantes.

As características posturais e morfológicas do sistema estomatognático estudadas nas crianças 
respiradoras orais apresentam a mesma freqüência com o avançar da idade segundo pesquisa de Cattoni et all (2007) ${ }^{26}$.

\section{A relação entre o estado nutricional, a respiração oral e a postura corporal}

O crescimento global das crianças com respiração oral pode ser prejudicado, bem como o estado nutricional ${ }^{9}$.

A respiração oral é uma característica adaptativa, cuja etiologia é multifatorial. É frequente em crianças em idade escolar e alguns estudos já relacionam com a persistência de alterações posturais ${ }^{27,28}$. A respiração oral crônica exige modificações posturais de partes anatômicas, como a mandíbula e a língua. Essas alterações podem interferir na direção do crescimento da mandíbula e dos dentes, apresenta como conseqüência uma adaptação de toda a musculatura facial ${ }^{29,30}$.

A alteração de qualquer parte do complexo orofacial manifesta-se não apenas localmente, mas perturbando o equilíbrio do sistema orgânico. O sistema estomatognático não pode separar-se de sua relação com as estruturas anatômicas da cabeça e do pescoço, devendo ser examinadas e tratadas integralmente ${ }^{31}$. Para isso, o paciente deve ser avaliado com enfoque nas características da síndrome da respiração oral, que analisadas em conjunto e não isoladamente fecham o diagnóstico, permitindo um tratamento em equipe ${ }^{32}$.

Naturalmente os humanos são respiradores nasais, e essa é a respiração fisiológica e vital a qual favorece o crescimento e um bom desenvolvimento das funções orofaciais, além do desenvolvimento físico e intelectual. Portanto, a respiração correta, além de proporcionar o necessário aporte de oxigênio para o metabolismo celular, sendo responsável pela produção de energia, garante o correto desenvolvimento anatômico e funcional das mais diversas estruturas do corpo, influencia diretamente a manutenção da organização esquelética, dentária e muscular do sistema estomatognático ${ }^{18,31,33}$.
Todo o desequilíbrio do sistema estomatognático poderá repercutir sobre o conjunto do sistema postural, do mesmo modo que alterações posturais poderão interferir negativamente no sistema estomatognático ${ }^{34,35}$.

A hipótese de que crianças com respiração oral podem desenvolver alterações no estado nutricional não foi confirmada no estudo de Cunha et al. ${ }^{10}$, onde foi observado a predominância de indivíduos eutróficos e a ausência de diferença significante nas freqüências de crianças com baixo peso e sobrepeso entre os grupos de Respiradores Orais e Nasais.

Também não foi encontrado na literatura consultada relação direta entre a alteração no modo respiratório e alterações de peso e estatura em crianças. As possíveis explicações para estes resultados podem estar no fato de as crianças respiradoras orais não terem apresentado um quadro grave da rinite alérgica, sendo diagnosticado apenas um problema leve sem comprometimento direto com o crescimento ${ }^{10}$.

\section{CONCLUSÃO}

Segundo os artigos pesquisados é a obesidade, dentre os distúrbios nutricionais, que gera maior número de problemas musculoesqueléticos, pois dificulta o controle da postura corporal.

Nos dias atuais, doenças da coluna têm sido consideradas um sério problema de saúde pública, pois se apresentam com elevada incidência na população, incapacitando-a temporária ou definitivamente para atividades profissionais. No que se refere à respiração, conclui-se que apesar de haver fortes argumentos teóricos buscando explicar uma possível influência da respiração oral sobre o estado nutricional, os estudos de campo até o momento não conseguiram confirmar tal hipótese, por esta razão torna-se relevante continuar pesquisando sobre estas relações. 


\begin{abstract}
Background: the relationship between nutritional status, oral breathing and body posture. A balanced diet can provide adequate nutritional status that certainly contributes to a desirable condition of posture and nasal breathing for the subject. With regard the respiratory and breathing in children, since there is more change in sleep, decreased carbohydrate intake and increased intake of lipids, there may be also an association between oral breathing and nutritional status. Purpose: to illustrate the possible relationships between nutritional status, body posture and oral breathing in children, through a theoretical study. Conclusion: according to the reviewed studies, it is obesity, among nutritional disturbances, which generates a larger number of musculoskeletal disorders, such as impeding the control of body posture. We conclude that despite strong theoretical arguments seeking to explain a possible influence of mouth breathing on nutritional status, field studies, up to date, have failed to confirm this hypothesis, for this reason it is relevant to continue the research on these relationships.
\end{abstract}

KEYWORDS: Posture; Respiration; Mouth Breathing; Nutritional Status; Child

\section{REFERÊNCIAS}

1. Mello ED de. O que significa a avaliação do estado nutricional. J. Pediatr. [online]. 2002; [Acesso em 20 de Março]; 78(5):357-8. Disponível em: http://www. scielo.br/pdf/jped/v78n5/7805357.pdf.

2. Cuervo MRM.; Aerst DRG de C. and Halpern R. Vigilância do estado nutricional das crianças de um distrito de saúde no Sul do Brasil. J. Pediatr. (Rio J.) [online]. 2005; [Acesso em 25 de Junho]; 81(4):325-31. Disponível em: http://www.scielo.br/ pdf/jped/v81n4/v81n4a11.pdf.

3. Castro TG de et al. Caracterização do consumo alimentar, ambiente socioeconômico e estado nutricional de pré-escolares de creches municipais. Rev. Nutr. [online]. 2005; [Acesso em 22 de Abril]; 18(3): 321-30. Disponível em: http://www.scielo.br/ $\mathrm{pdf} / \mathrm{rn} / \mathrm{v} 18 \mathrm{n} 3 / \mathrm{a} 04 \mathrm{v} 18 \mathrm{n} 3$. pdf.

4. Yi LC; Jardim JR; Inoue DP and Pignatari SSN. Relação entre a excursão do músculo diafragma e as curvaturas da coluna vertebral em crianças respiradoras bucais. J. Pediatr. (Rio J.) [online]. 2008; [Acesso em 19 de Junho]; 84(2): 171-7. Disponível em: http://www.scielo.br/pdf/jped/v84n2/ en_v84n2a14.pdf.

5. Bachiega CMMV. A prevalência de sobrepeso e obesidade em escolares e a influência nas alterações posturais do aparelho locomotor. Dissertação (mestrado) - Universidade Estadual Paulista, Faculdade de Medicina de Botucatu, 2006.

6. Batista LRV; Moreira EAM and Corso ACT. Alimentação, estado nutricional e condição bucal da criança. Rev. Nutr. [online]. 2007; [Acesso em 19 de Junho] 20(2): 191-6. Disponível em: http://www. scielo.br/pdf/rn/v20n2/08.pdf.
7. Gomes F da Silva; Anjos LA dos and Vasconcellos MTL de. Associação entre o estado nutricional antropométrico e a situação sócio-econômica de adolescentes em Niterói, Rio de Janeiro, Brasil. Cad. Saúde Pública [online]. 2009; [Acesso em 05 de Abril]; 25(11):2446-54. Disponível em: http:// www.scielosp.org/pdf/csp/v25n11/14.pdf .

8. Arruda MF de; Simões MJS. Perfil do excesso de peso na infância e sua influência sobre o sistema musculoesquelético de escolares. Cinergis [online]. 2007; [Acesso em 19 de Março]; 8(2):3747. Disponível em: http://online.unisc.br/seer/index. php/cinergis/article/view/560/1035.

9. Cunha DA da. A respiração oral em crianças repercute no estado nutricional? Dissertação apresentada ao colegiado do Programa de Pós-Graduação em Nutrição do Departamento de Nutrição do Centro de Ciências da Saúde da Universidade Federal de Pernambuco, para obtenção do grau de mestre em Nutrição. Recife, 2005.

10. Cunha DA da et al. A respiração oral em crianças e suas repercussões no estado nutricional. Rev. CEFAC [online]. 2007; [Acesso em 23 de Junho]; 9(1): 47-54. Disponível em: http://www.scielo.br/pdf/ rcefac/v9n1/v9n1a05.pdf.

11. Andrade FV de; Andrade DV de; Araújo AS; Ribeiro ACC; Deccax LDG; Nemr K. Alterações estruturais de órgãos fonoarticulatórios e más oclusões dentárias em respiradores orais de 6 a 10 anos. Rev CEFAC, São Paulo. Jul - set, 2005; [Acesso em 20 de Junho]; 7(3): 318-25. Disponível em: http://www.revistacefac.com.br/revista73/ artigo\%205.pdf.

12. Sigolo $\mathrm{C}$ et al. Ocorrência de movimentos primários de língua em crianças respiradoras oronasais. Rev. CEFAC [online]. 2008; [Acesso em 
05 de Março]; 10(1): 51-7. Disponível em: http:// www.scielo.br/pdf/rcefac/v10n1/08.pdf.

13. Di Francesco RC, Passeroti G, Paulucc B, Miniti A. Respiração oral na criança: repercussões diferentes de acordo com o diagnóstico. Rev Bras Otorrinolaringol. 2004; [Acesso em 20 de Julho]; 7(5):665-70. Disponível em: http://www.scielo.br/ pdf/\%0D/rboto/v70n5/a14v70n5.pdf.

14. Carvalho GD. Alterações alimentares e do apetite. In: Carvalho GD. S.O.S. respirador bucal. São Paulo: Lovise; 2003. p. 137-44.

15. Costa JR; Pereira SRA; Mitri G; Motta JC; Pignatari SSN.; Weckx LLM. Relação da oclusão dentária com a postura de cabeça e coluna cervical em crianças respiradoras orais. Rev Paul Pediatria. 2005; [Acesso em 25 de Abril]; 23(2): 88-93. Disponível em: http://www.scielo.br/pdf/rcefac/ v11s3/a04v11s3.pdf.

16. Rodrigues HOSN; Stella Rocha Faria; Fabiane da Silva Guedes de Paula; Andréa Rodrigues Motta. Ocorrência de respiração oral e alterações miofuncionais orofaciais em sujeitos em tratamento ortodôntico. Rev CEFAC, São Paulo. Jul - Set, 2005; [Acesso em 25 de Junho]; 7(3): 356-62. Disponível em: http://www.revistacefac.com.br/ revista73/artigo\%2010.pdf.

17. Andrade e Silva MA de; Natalini V; Ramires RR and Ferreira LP. Análise comparativa da mastigação de crianças respiradoras nasais e orais com dentição decídua. Rev. CEFAC [online]. 2007; [Acesso em 21 de Março]; 9(2): 190-8. Disponível em: http://www.scielo.br/pdf/rcefac/v9n2/a07v9n2. pdf.

18. Marchesan IQ. Avaliação e terapia dos problemas da respiração. In: Marchesan IQ. Fundamentos em fonoaudiologia: aspectos clínicos da motricidade oral. Rio de Janeiro: Guanabara Koogan; 1998. p. 23-36.

19. Carnevalli D.B.; Nozaki V.T.; Araújo A.P.S. de. Avaliação do Estado Nutricional de Crianças Respiradoras Orais - Sua Relação com a Obesidade. Revista Saúde e Pesquisa, mai/ago. 2009; [Acesso 28 de Outubro]; 2( 2): 185-93, ISSN 1983-1870. Disponível em: http://www.cesumar.br/ pesquisa/periodicos/index.php/saudpesq/article/ view/986/782.

20. Oliveira AC; Anjos CAL; Silva EHAA; Menezes PL. Aspectos indicativos de envelhecimento facial precoce em respiradores orais adultos. Pró-Fono Revista de Atualização Científica, Barueri (SP). Jul - Set, 2207; [Acesso em 14 de Junho]; 19(3):30512. Disponível em: http://www.scielo.br/pdf/pfono/ v19n3/en_a09v19n3.pdf.

21. Neiva PD; Kirkwood RN. Mensuração da amplitude de movimento cervical em crianças respiradoras orais. Rev. bras. fisioter., São
Carlos. Set/Out, 2007; [Acesso em 14 de Agosto]; 11(5):355-60. Disponível em: http://www.scielo.br/ pdf/rbfis/v11n5/en_a05v11n5.pdf.

22. Campanha SMA; Freire LMS; Fontes MJF. O impacto da asma, da rinite alérgica e da respiração oral na qualidade de vida de crianças e adolescentes. Rev. CEFAC. Out - Dec, 2008; [Acesso em 18 de Julho]; 10(4): 513-9. Disponível em: http://www. scielo.br/pdf/rcefac/v10n4/v10n4a11.pdf.

23. Souchard PH. Respiração. 3a ed. São Paulo: Summus Editorial, 1989.

24. Bankoff ADP; Zamai CA; Schimdt A; Ciol P; Barros DD. Estudo das alterações morfológicas do sistema locomotor: postura corporal $\mathrm{x}$ obesidade. R. da Educação Física/UEM Maringá. 2o Sem, 2003; [Acesso em 20 de Julho]; 14(2): 41-8. Disponível em: http://periodicos.uem.br/ojs/index. php/RevEducFis/article/view/3468/2474.

25. Junior APS; Sigulem DM; Novo NF; Juliano Y. Postura e hábitos posturais em crianças obesas. III Jornada de Ciências da Saúde; Maio de 2008; Faculdades Integradas de Bauru - FIB. Bauru São Paulo: FIBBAURU; 2008; [Acesso em 22 de Março]. Disponível em: http://www.fibbauru. br/files/Postura \%20e\%20h\%C3\%A1bitos $\% 20$ posturais\%20em\%20crian\%C3\%A7as\%20obesas. pdf.

26. Cattoni DM; Fernandes FDM; Di Francesco RC and Latorre MRDO. Características do sistema estomatognático de crianças respiradoras orais: enfoque antroposcópico. Pró-Fono R. Atual. Cient. [online]. 2007; [Acesso em 19 de Junho]; 19(4): 347-51. Disponível em: http://www.scielo.br/pdf/ pfono/v19n4/a04v19n4.pdf.

27. Neiva PDI. Orientação e posição da cabeça, escápula e coluna torácica em crianças respiradoras orais. Dissertação apresentada ao Programa de Pós-graduação em Ciências da Reabilitação da Escola de Educação Física, Fisioterapia e Terapia Ocupacional da Universidade Federal de Minas Gerais, como requisito parcial para obtenção do grau de Mestre em Ciências da Reabilitação.Belo Horizonte, 2008.

28. Basso DBA; Souza JA; Pasinato F; Corrêa ECR; Silva AMT da. Estudo da postura corporal em crianças com respiração predominantemente oral e escolares em geral. Saúde, Santa Maria, 2009. [Acesso em: 20 de Novembro de 2010] 35(1):21-27. Disponível em: http://w3.ufsm.br/ revistasaude/2009/35(1)21-7.2009.pdf

29. Krakauer LH; Guilherme A. The Relantionship between Mouth Breathing and Postural Alterations in Children: A Descriptive Analysis. R Dental Press Ortodon Ortop Facial, Maringá. Set./Out. 2000. [Acesso em: 25 de Novembro de 2010] 5(5):85-92, http://www.dentalpress.com.br/artigos/pdf/161.pdf 
30. Motonaga SM; Berte LC; Anselmo-Lima WT. Respiração bucal: causas e alterações no sistema estomatognático. Revista Brasileira de Otorrinolaringologia Julho - Agosto de 2000; [Acesso em: 10 de Novembro de 2010] 66(4):373-9. Disponível em: http://www.rborl.org.br/conteudo/ acervo/print_acervo.asp?id=2482

31. Silveira MC da et al. Proposta de documentação fotográfica em motricidade oral. Rev. CEFAC [online]. 2006; [Acesso em 18 de Junho]; 8(4): 485-92. Disponível em: http://www.scielo.br/pdf/ rcefac/v8n4/v8n4a09.pdf.

32. Filho DI; Bertolini MM; Lopes ML. Contribuição multidisciplinar no diagnóstico e no tratamento das obstruções da nasofaringe e da respiração bucal. $\mathrm{R}$ Clin Ortodon Dental Press, Maringá. Dez./Jan. 2006. [Acesso em: 18 de Novembro de 2010] 4(6):90-102. Disponível em: http://www.aipro.info/ drive/File/195.pdf

33. Mitre El. Conhecimentos essenciais para atender bem a inter-relação Otorrinolaringologia e Fonoaudiologia/organizadores: Edson Ibrahim Mitre, Irene Queiroz Marchesan, Jaime Luiz Zorzi São José dos Campos: Pulso; 2003.

34. Ferla A; Silva AMT da; Corrêa, Eliane CR. Atividade eletromiográfica dos músculos temporal anterior e masseter em crianças respiradoras orais e em respiradoras nasais. Rev Bras Otorrinolaringol, 2008; [Acesso em 10 de Abril]; 74(4): 588-95. Disponível em: http://www.scielo.br/pdf/rboto/ v74n4/en_a17v74n4.pdf.

35. Amantéa DV; Novaes AP; Campolongo GD; Barros TP De. A importância da avaliação postural no paciente com disfunção da articulação temporomandibular. Acta Ortop Bras, Jul - Set, 2004; [Acesso em 14 de Março]; 12(3): 155-9. Disponível em: http://www.scielo.br/pdf/aob/v12n3/ v12n3a04.pdf.

36. Corrêa E.C.R., Bérzin F. Temporomandibular disorder and dysfunctional breathing. Braz $\mathrm{J}$ Oral Sci, 2004; 3(10):498-502.
http://dx.doi.org/10.1590/S1516-18462011005000096

RECEBIDO EM: 27/08/2010

ACEITO EM: 09/12/2010

Endereço para correspondência:

Patricia Girarde Machado

Floriano Peixoto 361 ap 201, Centro

Santa Maria, Rio Grande do Sul, Brasil

E-mail: pati_girarde@ hotmail.com 